\title{
PENGARUH BENTUK LATIHAN MENGGUNAKAN DUA MEJA TERHADAP KETEPATAN FOREHAND DALAM PERMAINAN TENIS MEJA
}

\author{
Melya Nur Herliana \\ Universitas Siliwangi \\ e-mail : melya.nh22@unsil.ac.id
}

\begin{abstract}
Abstrak
Penelitian untuk memperoleh informasi tentang pengaruh bentuk latihan menggunakan dua meja terhadap ketepatan forehand dalam permainan tenis meja pada UKM Tenis Meja Universitas Siliwangi Kota Tasikmalaya. Metode penelitian yang digunakan adalah metode eksperimen. Populasi penelitian adalah UKM tenis Meja Universitas Siliwangi Kota Tasikmalaya sebanyak 45 orang dan dipilih 20 orang untuk ditentukan sebagai sampel dengan menggunakan teknik purposive sampling. Instrument dalam penelitian ini adalah tes forehand. Berdasarkan hasil pengelolahan data dengan uji statistik, ternyata secara empiric terdapat pengaruh yang sigbifikan bentuk latihan menggunakan dua meja Universitas Siliwangi Kota Tasikmalaya hasilnya hipotesis diterima dan termasuk kategori cukup. Berdasarkan hasil penelitian diatas, penulis menyarankan kepada berbagai pihak yang terkait dengan bidang keolahragaan, khususnya dengan cabang olahraga tenis meja, bahwa untuk menghasilkan ketepatan forehand hendaknya mencoba menerapkan bentuk latihan menggunakan dua meja dalam upaya meningkatkan ketepatan forehand atlet.
\end{abstract}

Kata Kunci : Latihan Menggunakan Dua Meja, Forehand, Tenis Meja

\begin{abstract}
Research to obtain information about the effect of the form of training uses two tables on the accuracy of forehand in table tennis at the Siliwangi University Table Tennis UKM in Tasikmalaya City. The research method used is the experimental method. The population of the study was 45 people from the Table Tennis University of Siliwangi City in Tasikmalaya and 20 people were selected to be determined as samples using purposive sampling technique. The instrument in this study was a forehand test. Based on the results of managing the data with statistical tests, it turns out that empirically there is a significant effect of the form of training using two tables of Siliwangi University in Tasikmalaya City, the results of which the hypothesis is accepted and includes enough categories. Based on the results of the above research, the authors suggest to various parties related to the field of sports, especially with the table tennis sport, that to produce forehand accuracy should try to apply the form of training using two tables in an effort to improve the accuracy of the athlete's forehand.
\end{abstract}

Keywords: Exercise Using Two Tables, Forehand, Table Tennis 


\section{PENDAHULUAN}

Dewasa ini perkembangan olahraga mengalami kemajuan yang sangat pesat, baik ditingkat nasional ataupun internasional. Hal ini terjadi karena masyarakat semakin sadar akan pentinya kegiatan olahraga, baik itu untuk tujuan rekreasi, kesehatan maupun untuk meningkatkan prestasi. Dengan melihat perkembangan olahraga yang semakin pesat, pemerintah terus menerus mengadakan pembinaan dan pengembangan olahraga yang merupakan bagian upaya meningkatkan kualitas hidup masyarakat Indonesia. Di Indonesia cabang olahraga tenis meja semakin hari semakin meningkat dilihat dari banyaknya tempat latihan atau klub tenis meja disetiap daerah sutarmi dalam (Rachman, Sulaiman, \& Rumini, 2017). Tenis Meja adalah olahraga semua umur dan bisa dianggap sebagai rekreasi maupun sebagai pemacu prestasi. Keduanya bisa dinikmati sekaligus, tetapi untuk memperlakukannya sebagai olahraga, perlu dipahami dulu berbagai teknik dan gaya permainan yang ada (Simpson, 1981), Tenis Meja adalah raket yang paling terkenal di dunia dan jumlah partisipasinya menempati urutan kedua (Hodges, 1996), tenis meja adalah suatu permainan yang menggunakan meja sebagai lapangan yang dibatasi oleh jaring (net) yang menggunakan bola kecil yang terbuat dari celluloid dan permainannya menggunakan pemukul atau yang disebut dengan bet (Depdiknas, dalam (Tomoliyus, n.d.). Jadi tenis meja adalah permainan bola kecil yang unik dan bersifat rekreatif yang mana permainan ini sangat digemari oleh anak-anak atau orang tua, dalam permainan tenis meja tidak perlu memakan ruangan yang terlalu besar, masyarakat hanya menyediakan meja dan bat untuk melakukan olahraga tenis meja.

Pemain apabila ingin menguasai permainan tenis meja harus mempunyai kemampuan dalam penguasaan teknik dasar dan kondisi fisik yang baik. Teknik dasar dalam dalam permainan tenis meja seperti memegang bet (grip), teknik stance, teknik gerakan kaki dan teknik pukulan. Hal yang mendasar bagi pemain tenis meja harus mampu menguasai teknik pukulan, teknik pukulan dalam permainan tenis meja dibagi 2 pukulan forehand dan backhand. Pukulan forehand adalah pukulan dengan posisi pegangan telapak tangan menghadap ke depan dan posisi memukul dari arah kanan badan, pukulan forehand mempunyai kekuatan yang besar dibandingkan dengan pukulan backhand karena posisi memukul tidak terhalangi oleh tubuh (Asri, Soegiyanto, \& Mukarromah, 2017). Untuk menguasai teknik pukulan forehand maka pemain harus banyak melakukan latihan secara kontinu dan harus mempunyai komponen kondisi yang mendukung terhadap peningkatan pukulan forehand.

Pukulan forehand didukung oleh beberapa komponen kondisi fisik seperti kekuatan, power, kelincahan dan fleksibilitas. Komponen kondisi fisik ini harus dimiliki oleh pemain untuk mendapatkan pukulan forehand yang baik. Namun ada hal yang penting yang harus pemain punya selain daripada komponen kondisi fisik yaitu pemain harus mempunyai ketepatan yang baik dalam menempatkan bola di meja lawan, Namun melihat dari kenyataannya masih ada pemain yang tidak mempunyai ketepatan dalam melakukan pukulan forehand terutama untuk para pemain unit kegiatan mahasiswa tenis meja Universitas Siliwangi hal ini dilihat dari setiap latihan dan pertandingan terkadang pukulan forehand yang dilakukanya keras namun tidak tepat sasaran walaupun pukulan itu keras namun tidak tepat sasarannya maka pukulan tersebut akan dengan mudah dibalikan oleh lawan atau bolanya tidak masuk, padahal ketepatan sangat penting sekali untuk pemain tenis meja. Ketepatan adalah mengarahkan sesuatu yang sesuai dengan tujuan atau target, ketepatan adalah kemampuan seseorang dalam mengarahkan suatu gerakan pada obyek sesuai dengan sasaran yang dikendalikan oleh bagian tubuh tertentu Tomoliyus dalam (Saputro, n.d.). banyak hal untuk dapat meningkatkan ketepatan terutama dengan cara berlatih yang konsisten dengan 
berlatih diberikan sasaran dalam setiap latihan dengan sasaran tersebut berpindah-pindah apabila sasaran pertama sudah bisa dilewati dengan baik. Dengan ini peneliti membuat program latihan untuk melatih ketepatan dengan menempatkan 2 meja tenis meja untuk melatih ketepatan. Penempatan 2 meja dilakukan agar pemain bisa berpindah-pindah tempat dalam melakukan forehand namun dengan adanya sasaran atau target yang dituju.

\section{BAHAN DAN METODE/METODOLOGI}

Penelitian ini dilakukan di Unit Kegiatan Mahasiswa (UKM) Tenis Meja Universitas Siliwangi Kota Tasikmalaya dengan sampel mahasiswa UKM tenis meja sebanyak 20 orang. Pelaksanaan penelitian ini dilaksanakan selama 2 bulan dengan program latihan dilakukan seminggu 3 kali bertempat di GOR Mashud Wisnu Saputra Universitas Siliwangi hal ini dikarenakan penelitian ini menggunakan metode eksperimen. Metode eksperimen adalah pengambilan data dengan adanya perlakuan, eksperimen adalah penelitian yang dilakukan secara ketat untuk mengetahui hubungan sebab akibat di antara variable, salah satu ciri utama dari penelitian eksperimen adalah adanya perlakuan (treatment) yang dikenakan kepada subjek atau objek penelitian (Maksum, 2014). Untuk mendapatkan data maka dilakukan tes dalam mengukur kemampuan keterampilan forehand. Tes adalah alat untuk mendapatkan informasi yang digunakan kepada objek atau subjek. Dengan tes pelatih atau pendidik dapat memperoleh data-data yang tepat, terutama mengukur keterampilan olahraga atau mengukur kebugaran jasmani. Tes adalah merupakan suatu alat yang digunakan dalam memperoleh data dari suatu objek yang akar di ukur (Nurhasan \& Narlan, 2017). Tes secara umum adalah suatu alat pengumpul data dan sebagai dasar penilaian dalam proses pendidikan, dalam bentuk tugas yang harus dikerjakan oleh anak didik sehingga menghasilkan nilai tentang tingkah laku (Widiastuti, 2011).

Instrument tes yang digunakan adalah instrument forehand test, forehand test ini mempunyai validitas 0,615 dan realibilitas 0,738 .
Peralatan tes yang digunakan stopwatch, lima buah bola tenis meja, bat, sebuah meja tenis meja yang dilipat, sebuah karton berukuran 10x5x3 cm yang dapat ditempelkan dengan pines pada sudut samping kiri belakang meja, dingding atau tiang untuk sandaran bagian meja tenis yang didirikan tegak lurus pada bagian meja yang horizontal, pita kertas lebar $2 \mathrm{~cm}$ yang direkatkan pada bagian meja yang didirikan tegak lurus, sejajar dengan bagian meja yang horizontal dan berjarak $15 \mathrm{~cm}$ dari permukaan meja., blangko dan alat tulis untuk mencatat hasil tes. Pelaksanaan testee berdiri dibelakang atau lanjutan bagian meja yang horizontal, dengan sebuah bat dan bola ditangan. Pada aba-aba "Ya" testee menjatuhkan diatas meja dan memukul bola kebagian meja yang didirikan tegak lurus terhadap bagian meja yang horizontal. Testee berusaha memantulkan bola sebanyak-banyaknya dalam waktu 30 detik. Bila testee tidak mampu menguasai bola, ia dapat mengambil bola yang tersedia dikotak, menjatuhkannya di meja dan melanjutkan usaha memantulkan bola sebanyak-banyaknya dalam waktu yang tersedia. Seorang pembantu mengambil bola yang dikuasai testee dan memasukannya kembali kedalam kotak (Nurhasan \& Narlan, 2017).

\section{HASIL DAN PEMBAHASAN}

\section{A. Deskripsi Data}

Data yang diperoleh dalam penelitian ini dari hasil tes forehand dengan waktu 30 detik yang dilaksanakan pada tes awal dan tes akhir. Dari hasil tes tersebut diambil data hasil tes forehand yang penulis deskripsikan dalam tabel dibawah ini.

Tabel 1. Data Hasil Tes Awal dan Tes Akhir

\begin{tabular}{llll}
\multirow{2}{*}{ No } & \multirow{2}{*}{ Nama } & \multicolumn{2}{c}{ Tes forehand } \\
\cline { 3 - 4 } & & Tes Awal & Tes Akhir \\
\hline 1 & Agus & 22 & 21 \\
\hline 2 & Lupi & 22 & 23 \\
\hline 3 & Elin & 26 & 35 \\
\hline 4 & Azis & 28 & 36 \\
\hline 5 & Firda & 40 & 48 \\
\hline 6 & Torik & 20 & 30 \\
\hline 7 & Yusuf & 10 & 19 \\
\hline 8 & Budi & 18 & 27 \\
\hline 9 & Fajar & 14 & 23 \\
\hline 10 & Kurnianto & 23 & 31
\end{tabular}




\begin{tabular}{llll}
11 & Urip & 4 & 14 \\
\hline 12 & Uci & 13 & 22 \\
\hline 13 & Irfan & 20 & 29 \\
\hline 14 & Ristianto & 11 & 19 \\
\hline 15 & Fakhri & 14 & 23 \\
\hline 16 & Ade & 20 & 28 \\
\hline 17 & Andri & 10 & 19 \\
\hline 18 & Bambang & 11 & 24 \\
\hline 19 & Randi & 31 & 39 \\
\hline 20 & Alvian & 13 & 22
\end{tabular}

B. Pengujian Persyaratan Analisis

Setelah diperoleh data dari hasil tes forehand, selanjutnya dilakukan pengujian peersyaratan analisis menggunakan pendekatan statistik yang relavan. Adapun langkah-langkah yanng dilakukan dalam pengujian persyaratan analisis tersebut adalah sebagai berikut :

1. Penghitungan Skor Rata-rata, Standar Deviasi, dan Varians

Tabel 2. Hasil Perhitungan Rata-rata, Standar Deviasi dan Varians

\begin{tabular}{llll} 
Variabel & $\begin{array}{l}\text { Rata- } \\
\text { rata }\end{array}$ & $\begin{array}{l}\text { Standar } \\
\text { Deviasi }\end{array}$ & Varians \\
\hline Tes Awal & 19,1 & 9,2 & 84,64 \\
\hline Tes & 27,2 & 8,0 & 64,00
\end{tabular}

Akhir

2. Pengujian Normalitas Data

Hasil pengujian normalitas data dengan menggunakan rumus uji normalitas data melalui pendekatan chi-kuadrat dapat dilihat pada tabel berikut ini.

Tabel 3. Pengujian Normalitas Data

\begin{tabular}{|l|l|l|l|}
\hline $\begin{array}{l}\text { Variabel } \\
\text { Tes }\end{array}$ & $\begin{array}{l}\text { Nilai } \\
\chi^{2} \\
\text { hitung }\end{array}$ & $\begin{array}{l}\text { Nilai } \chi^{2} \\
\text { tabel } \\
(\alpha=0,05)\end{array}$ & Kesimpulan \\
\hline $\begin{array}{l}\text { Tes } \\
\text { Awal }\end{array}$ & 1,82 & 5,99 & Normal \\
\hline $\begin{array}{l}\text { Tes } \\
\text { Akhir }\end{array}$ & 1,57 & 5,99 & Normal \\
\hline
\end{tabular}

3. Pengujian Homogenitas

Untuk mengetahui homogeny tidaknya sampel yang akan diteliti, maka homogenitas sampel penelitian diolah dengan menggunakan pendekatan uji homogenitas.

Tabel 4. Pengujian Homogenitas

Variabel Tes Nilai F- Nilai F- Hasil Hitung tabel Pada

$(\alpha=0,05)$

$(20,20)$ $\left.\begin{array}{l}\text { Tes Awal } \\ \text { Tes Akhir }\end{array}\right\} \quad 1,01 \quad 2,12 \quad$ Homogen

C. Pengujian Hipotesis

Pengujian hipotesis ini dilakukan untuk memberikan apakah hipotesis yang penulis ajukan dalam penelitian ini diterima atau ditolak. Sehubungan dengan data dalam penelitian ini berdistribusi normal dan homogen, maka statistik yang digunakan adalah parametrik. Dengan demikian untuk keperluan pengujian hipotesis penelitian ditempuh analisis statistik dengan menggunakan uji kesamaan dua rata-rata uji satu pihak menggunakan uji t'. Adapun hasil pengujian hipotesis penelitian ini penulis sajikan pada tabel berikut ini.

Table 5. Analisis Data Peningkatan Hasil Latihan forehand

$\begin{array}{llll}\text { Variabel Tes } & \text { t'- } & \text { t'- Tabel Kesimpulan } \\ & \text { Hitung } & =0,975 \\ & & \text { dan dk } \\ & =19\end{array}$

Tes Awal $] \quad 2,79 \quad 1,73 \quad$ Signifikan

Tes Akhir diterima hipotesis (Ho) apabila t' $\leq 1,73$ dan tolak hipotesis jika t' $\geq 1,73$. Berdasarkan table tersebut diatas ternyata t' hitung lebih besar dari t' table dan berada di luar daerah penerimaan hipotesis. Dengan demikian hipotesis (Ho) ditolak pada taraf nyata $\alpha=0,05$. Ini berarti "terdapat pengaruh yang berarti bentuk latihan menggunakan dua meja terhadap ketepatan forehand dalam permainan tenis meja pada UKM Tenis Meja Universitas Siliwangi Kota Tasikmalaya". Peningkatan latihan ketepatan dengan dua meja disebabkan karena latihan yang dilakukan secara sistematis dan berulang-ulang serta menambah beban setiap kali melakukannya, hal ini menyebabkan para pemain menjadi ada peningkatan dalam melakukan latihan ketepatan. Latihan dengan dua meja menjadikan proses latihan tidak menjadi jenuh dikarenakan proses latihan dalam menempatkan sasaran atau target yang berubah-rubah pada meja membuat pemain lebih tertantang dan termotivasi dalam setiap latihannya. 


\section{KESIMPULAN DAN SARAN}

Kesimpulan

Sesuai dengan analisis dan pembahasan hasil penelitian yang diperoleh, maka dapat disimpulkan bahwa bentuk latihan menggunakan dua meja berpengaruh terhadap ketepatan forehand dalam permainan tenis meja pada UKM tenis meja Universitas Siliwangi

Saran

Berdasarakan hasil penelitian tersebut di atas, maka penulis mengajukna beberapa saran :

1. kepada pelatih tenis meja diharapkan untuk dapat menerapkan latihan forehand dengan dua meja untuk melatih ketepatan, karena hal ini telah terbukti secara ilmiah bahwa latihan dengan dua meja bisa meningkatkan ketepatan forehand dalam permainan tenis meja.

2. Bagi peneliti lainnya yang berminat pada masalah yang sama, penulis menyarankan agar melakukan penelitian dengan jumlah sampel yang lebih besar dan ruang lingkup yang lebih luas.

3. Penelitian lebih lanjut diharapkan dapat dilakukan terhadap aspek-aspek dan metode latihan lainnya.

\section{DAFTAR PUSTAKA}

Asri, N., Soegiyanto, \& Mukarromah, S. B. (2017). Pengaruh Metode Latihan Multiball dan Koordinasi Mata Tangan terhadap Peningkatan Keterampilan Forehand Drive Tenis Meja, 6(2), 179185.

Hodges, L. (1996). Tenis Meja Tingkat Pemula. Jakarta: PT. RajaGrafindo Persada.

Maksum, A. (2014). Metodologi Penelitian Dalam Olahraga. Surabaya: UNESA UNIVERSITY PRESS.

Nurhasan, \& Narlan, A. (2017). Tes dan Pengukuran Pendidikan Olahraga. Tasikmalaya: Pendidikan Jasmani Universitas Siliwangi.

Rachman, I., Sulaiman, \& Rumini. (2017). Journal of Physical Education and Sports Pengembangan Alat Pelontar Bola Tenis Meja ( Robodrill IR-2016 ) untuk Latihan Drill Teknik Pukulan Drive dan Spin Abstrak. Journal of Physical Education and Sports, 6(1), 50-56.

Saputro, R. D. (n.d.). Hubungan Koordinasi Mata TAngan dan power Lengan Terhadap Ketepatan Pukulan Forehand Drive Peserta Ekstrakulikuler Tenis Meja SMA 1 Tanjungsari Kabupaten Gunungkidul. Universitas Negeri Yogyakarta, 1-9.

Simpson, P. (1981). Tenis Meja. Jakarta: Dian Rakyat Jakarta.

Tomoliyus. (n.d.). PENGEMBANGAN INSTRUMEN KEMAMPUAN KETEPATAN FORE HAND, BACKHAND DRIVE DALAM, 1-14. Widiastuti. (2011). Tes Dan Pengukuran. Jakarta: PT. Bumi Timur Jaya. 